\title{
RECURSO DE AMPARO Y RECURSO DE CASACIÓN CONTENCIOSO-ADMINISTRATIVO: EL AGOTAMIENTO DE LA VÍA JUDICIAL PREVIA TRAS SU OBJETIVACIÓN
}

\author{
Amparo Appeal and Contentious-Administrative \\ cassation appeal: The exhaustion of prior judicial \\ remedies after their objectification
}

\author{
SUSANA GARCÍA COUSO \\ Universidad Rey Juan Carlos \\ Susana.garcia.couso@uric.es
}

Cómo citar/Citation

García Couso, S. (2021).

Recurso de amparo y recurso de casación contencioso-administrativo: el agotamiento de la vía judicial previa tras su objetivación. Anuario Iberoamericano de Justicia Constitucional, 25(1), 143-170. doi: https://doi.org/10.18042/cepc/aijc.25.06

\section{Resumen}

El trabajo tiene por objeto el estudio de la jurisprudencia del Tribunal Constitucional sobre el requisito del agotamiento de la vía judicial previa al recurso de amparo tras la reforma operada en el recurso de casación contencioso-administrativo por la Ley Orgánica 7/2015, de 21 de julio. Como ha apreciado el propio TC, el cambio sufrido como consecuencia de su objetivación, al incluir el requisito del «interés casacional objetivo para la formación de jurisprudencia» para su admisión, tiene una «indudable repercusión» en la satisfacción del citado requisito procesal.

\section{Palabras claves}

Recurso de amparo; agotamiento de los recursos previos; recurso de casación; interés casacional objetivo; incidente de nulidad de actuaciones.

\section{Abstract}

The purpose of the paper is to study the case law of the Constitutional Court on the requirement of exhaustion of the judicial means prior to the amparo appeal 
after the amendment carried out in the contentious-administrative appeal by Organic Law 7/2015 of July 21. As the Constitutional Court itself has appreciated, the change suffered as a consequence of its objectification has an «undoubted impact» on the satisfaction of the aforementioned procedural requirement, after having included the requirement of «objective cassational interest for the formation of case-law».

\section{Keywords}

Amparo appeal; exhaustion of remedies; cassation appeal; objective casational interest; appeal for annulment. 


\section{SUMARIO}

I. RECURSO DE CASACIÓN CONTENCIOSO-ADMINISTRATIVO, RECURSO DE AMPARO Y AGOTAMIENTO DE LA VÍA JUDICIAL PREVIA: 1. Recurso de casación contencioso-administrativo y recuso de amparo: «interés casacional objetivo para la formación de jurisprudencia» y «especial trascendencia constitucional». 2. El requisito del agotamiento de los medios de impugnación previos al amparo. II. EL AGOTAMIENTO DE LA VÍA JUDICIAL PREVIA AL RECURSO DE AMPARO EXIGE HABER INTENTADO EL RECURSO DE CASACIÓN: ATC 65/2018: 1. Antecedentes, objeto del recurso y resolución. 2. Sobre la decisión de la necesidad de la interposición del recurso de casación contencioso-administrativo antes de acudir al amparo constitucional: 2.1. Tribunal Supremo y agotamiento de la vía. 2.2. Tribunal Constitucional y Tribunal Europeo de Derechos Humanos. III. AGOTAMIENTO DE LA VÍA JUDICIAL PREVIA E INADMISIÓN DEL RECURSO DE CASACIÓN POR FALTA DE INTERÉS CASACIONAL: STC 112/2019: 1. Antecedentes. 2. Sobre el óbice procesal del agotamiento de la vía judicial previa al amparo: falta de interés casacional e incidente de nulidad de actuaciones. IV. AGOTAMIENTO DE LA VÍA JUDICIAL PREVIA E INADMISIÓN DEL RECURSO DE CASACIÓN POR INSUFICIENTE JUSTIFICACIÓN DEL INTERÉS CASACIONAL: STC 121/2019: 1. Posición del Tribunal Constitucional. 2. Posición del Tribunal Europeo de Derechos Humanos en relación con el recurso de amparo. V. A MODO DE CONCLUSIÓN. BIBLIOGRAFÍA.

\section{RECURSO DE CASACIÓN CONTENCIOSO-ADMINISTRATIVO, RECURSO DE AMPARO Y AGOTAMIENTO DE LA VÍA JUDICIAL PREVIA}

\section{RECURSO DE CASACIÓN CONTENCIOSO-ADMINISTRATIVO Y RECUSO DE AMPARO: «INTERÉS CASACIONAL OBJETIVO PARA LA FORMACIÓN DE JURISPRUDENCIA» $Y$ «ESPECIAL TRASCENDENCIA CONSTITUCIONAL"}

La disposición final tercera de la Ley Orgánica 7/2015, de 21 de julio, modificó la sección $3^{\text {a }}$ del capítulo III del título IV, integrada por los arts. 86 a 95, de la Ley 29/1998, de 13 de julio, reguladora de la Jurisdicción 
Contencioso-administrativa (LJCA), reformando la regulación del recurso de casación en el orden contencioso-administrativo; reforma que entró en vigor el 22 de julio de 2016.

Tras la nueva regulación, para la admisión del recurso de casación se hace necesario la invocación de una concreta infracción del ordenamiento jurídico, tanto procesal como sustantiva, o de la jurisprudencia, y que la Sala de lo Contencioso-administrativo del Tribunal Supremo estime que el recurso presenta «interés casacional objetivo para la formación de jurisprudencia» ${ }^{1}$. Requisito que se presenta como la "gran novedad» de la reforma (Fernández Farreres, 2015: 109), y que "se erige como la piedra angular» ${ }^{2}$ o "clave de bóveda» (Huelin Martínez de Velasco, 2017: 8) del nuevo modelo casacional.

Como se establece en el propio preámbulo ${ }^{3}$, con la nueva regulación, «la ley opta por reforzar el recurso de casación como instrumento por excelencia para asegurar la uniformidad en la aplicación judicial del derecho». La finalidad de la reforma es «que la casación no se convierta en una tercera instancia, sino que cumpla estrictamente su función nomofiláctica». Es por ello que la ley «diseña un mecanismo de admisión de los recursos basado en la descripción de los supuestos en los que un asunto podrá acceder al Tribunal Supremo por concurrir un interés casacional», y que la Sala de Casación podrá apreciar para admitir el recurso.

Lo expuesto pone de manifiesto las similitudes con el recurso de amparo objetivo regulado en la Ley Orgánica 6/2007, de 24 de mayo, de reforma de la Ley Orgánica 2/1979, de 3 de octubre, del Tribunal Constitucional (LOTC), que añade como requisito de admisibilidad la necesaria concurrencia de la «especial trascendencia constitucional» del recurso. Así ha quedado advertido por la doctrina al señalar que la reforma de la casación contencioso-admi-

1 Art. 88.1 LJCA: «El recurso de casación podrá ser admitido a trámite cuando, invocada una concreta infracción del ordenamiento jurídico, tanto procesal como sustantiva, o de la jurisprudencia, la Sala de lo Contencioso-Administrativo del Tribunal Supremo estime que el recurso presenta interés casacional objetivo para la formación de jurisprudencia».

2 ATS de 19 de junio de 2017 (RQ 273/2917).

3 Dice el preámbulo: «Con la finalidad de que la casación no se convierta en una tercera instancia, sino que cumpla estrictamente su función nomofiláctica, se diseña un mecanismo de admisión de los recursos basado en la descripción de los supuestos en los que un asunto podrá acceder al Tribunal Supremo por concurrir un interés casacional. Así, la Sala de casación podrá apreciar que en determinados casos existe interés casacional objetivo, motivándolo expresamente en el auto de admisión. El recurso deberá ser admitido en determinados supuestos, en los que existe la presunción de que existe interés casacional objetivo». 
nistrativa «sigue la senda marcada por el amparo constitucional» (Fernández Farreres, 2015: 110).

Con la reforma operada por la citada ley orgánica, se configuró una nueva regulación del trámite de admisión del recurso de amparo basado en la verificación por el Tribunal Constitucional de la existencia de especial trascendencia constitucional del recurso interpuesto, y se potenció la intervención de la jurisdicción ordinaria en la tutela de los derechos y libertades fundamentales a través de la modificación del incidente de nulidad de actuaciones (art. 241 Ley Orgánica del Poder Judicial; en adelante, LOPJ). Con dichas medidas se intentaba solventar el principal problema de la jurisdicción constitucional: la sobrecarga de trabajo generada por el crecimiento del número de recursos de amparo, así como «reordenar la dedicación» que se «otorga a cada una de sus funciones para cumplir adecuadamente con su misión constitucional».

Ambos recursos se han objetivado con las consecuencias que de ello se derivan. No todos los recursos interpuestos serán necesariamente objeto conocimiento por los tribunales respectivos. Únicamente lo serán, en el caso del amparo, aquellos que por atender "a su importancia para la interpretación de la Constitución, para su aplicación o general eficacia, y para la determinación del contenido y alcance de los derechos fundamentales» [art. 50.1.b) LOTC], justifican su control y decisión ${ }^{4}$, y, en el caso de la casación, aquellos que se identifiquen con los supuestos previstos en el art. 88.2 y 3 LJCA y sirvan para la formación de jurisprudencia. En ambos, recurso de casación contencioso-administrativo y recurso de amparo, el interés del recurrente permanece, pero la finalidad perseguida, tanto en uno como otro, es objetiva. Es decir, que se emita por los Altos Tribunales un pronunciamiento que va más allá del efecto producido en el caso concreto.

El propio Tribunal Constitucional ha reconocido, como veremos, que el cambio sufrido en el recurso de casación contencioso-administrativo tras la reforma operada por la Ley Orgánica 7/2015, de 21 de julio, «tiene indudable repercusión en la satisfacción del requisito de agotamiento de la vía judicial previa que rige en el recurso de amparo». La modificación sustancial del criterio de admisión ha llevado al Tribunal a plantearse, desde esta nueva perspectiva, el citado requisito, pronunciándose tanto acerca de la exigencia de haberse intentado su interposición, como sobre la posible falta de agotamiento tras haber sido inadmitido el recurso de casación por falta de interés casacional objetivo o por la insuficiente justificación del mismo.

4 El TC, en el FJ 2 de la STC 155/2009, elaboró una lista de «casos», no cerrada, «en los que un recurso de amparo tiene especial trascendencia constitucional». 


\section{EL REQUISITO DEL AGOTAMIENTO DE LOS MEDIOS DE IMPUGNACIÓN PREVIOS AL AMPARO}

La Ley Orgánica del Tribunal Constitucional establece que las violaciones de los derechos y libertades susceptibles de amparo constitucional podrán dar lugar al recurso de amparo siempre que, entre otros requisitos, se hayan agotado todos los medios de impugnación previstos por las normas procesales para el caso concreto [arts. 43.1 a) y 44.1 a) LOTC]. Dicho requisito exige la interposición de los recursos procedentes. Para el Tribunal, su pronunciamiento debe ser subsidiario del judicial, ya que es a los órganos judiciales a quienes corresponde reparar las presuntas violaciones de derechos fundamentales. La subsidiariedad del amparo tiene como finalidad evitar que los jueces y tribunales ordinarios queden privados de su función, constitucionalmente atribuida, de tutelar los derechos fundamentales 5 . Pero no siempre es fácil determinar cuáles son estos. Puede ocurrir que de interponer un recurso manifiestamente improcedente, el recurso de amparo se inadmita por extemporáneo. Razón por la cual el Tribunal se ha tenido que pronunciar al respecto en numerosos asuntos. Precisamente, tanto en el ATC 65/2018, de 18 de junio, como en la STC 112/2019, de 3 de octubre, objeto de este estudio, el Tribunal ha apreciado en la cuestión procesal del correcto agotamiento de la vía judicial previa al amparo en relación con el recurso de casación contencioso-administrativo objetivo, la especial trascendencia constitucional de los recursos de amparo interpuestos.

Con carácter general, sus pronunciamientos respecto del citado requisito procesal, se han basado, por un lado, en la apreciación de lo que es un recurso manifiestamente improcedente, y, por otro, en lo que es un recurso útil y pertinente. La armonización de las exigencias del principio de seguridad jurídica (art. 9.3 CE) y el derecho a la tutela judicial efectiva (art. 24.1 CE) han conducido al Tribunal a una aplicación restrictiva del concepto de recurso manifiestamente improcedente que limita «a los casos en que tal improcedencia derive de manera terminante, clara e inequívoca del propio texto legal, sin dudas que hayan de resolverse con criterios interpretativos de alguna dificultad $»^{6}$. Y ello porque «el respeto debido al derecho de la parte a utilizar cuantos recursos considere útiles para la defensa de sus intereses impide exigirle que se abstenga de emplear aquellos cuya improcedencia sea

5 También se pretende evitar que «quede abierta una vía de intersección de la jurisdicción constitucional con la ordinaria, que, de forma indirecta, provocaría una indeseable inseguridad jurídica» (STC 38/2020, de 25 de febrero, FJ 3).

6 ATC 198/2010, de 21 de diciembre, FJ 3, y 112/2019, de 3 de octubre, FJ 3 e). 
razonablemente dudosa y, en consecuencia, que asuma el riesgo de incurrir en una falta de agotamiento de la vía judicial previa» ${ }^{7}$. La extemporaneidad solo se produce para el Tribunal si es posible advertir que el recurrente ha actuado "con una intención meramente dilatoria o defraudadora del carácter preclusivo y perentorio del plazo para demandar en amparo» ${ }^{8}$. En definitiva, se inadmiten por extemporáneos aquellos recursos cuya improcedencia derive claramente de la ley, pues solo así es posible advertir en el recurrente una intención dilatoria.

Dicho lo anterior, se ha de señalar que para el Tribunal el óbice de la falta de agotamiento de la vía judicial previa «no sólo concurre cuando no se ejercitan los recursos procedentes, sino también cuando el ejercicio de los mismos es defectuoso, bien desde el punto de vista temporal, por ejercicio extemporáneo de los mismos, bien desde el punto de vista formal» ${ }^{9}$. La interposición defectuosa de un recurso pertinente es también motivo de inadmisión del recurso de amparo por incumplimiento de las exigencias del principio de subsidiariedad «que caracteriza el proceso constitucional de amparo»"

\section{EL AGOTAMIENTO DE LA VÍA JUDICIAL PREVIA AL RECURSO DE AMPARO EXIGE HABER INTENTADO EL RECURSO DE CASACIÓN: ATC 65/2018}

La primera resolución en la que el Tribunal aborda la cuestión del agotamiento de la vía judicial en relación con el recurso de casación contencioso-administrativo por interés casacional objetivo es el ATC 65/2018, de 18 de junio, dictado por la Sección Primera del Tribunal Constitucional.

\section{ANTECEDENTES, OBJETO DEL RECURSO Y RESOLUCIÓN}

Ante el Tribunal se interpuso demanda de amparo contra el auto de la Sección Primera de la Sala de lo Contencioso-Administrativo del Tribunal Superior de Justicia de Murcia, que desestimó, a su vez, el recurso de reposición interpuesto contra la providencia que acordó inadmitir a trámite el incidente de nulidad de actuaciones formulado frente a la sentencia desestimatoria del recurso contencioso-administrativo planteado por el demandante de amparo.

\section{Ibid.}

8 Por todas, STC 198/2010, FJ 3.

9 STC 83/2018, de 16 de julio, FJ 2.

10 STC 9/1992, de 16 de enero, FJ 1. 
El incidente de nulidad se inadmitió porque el órgano judicial consideró que debía haberse intentado previamente el recurso de casación. El órgano judicial declaraba que el art. 241.1 LOPJ exige la firmeza de la resolución antes de acudir al incidente de nulidad de actuaciones, por lo que se debían agotar todos los recursos que en cada caso fueran procedentes, y el de casación lo era dado que únicamente a la Sección de Admisión de la Sala Tercera del Tribunal Supremo correspondía decidir su apreciación. En definitiva, el recurrente debió preparar recurso de casación y solo de no admitirse la sentencia devenía firme.

El demandante de amparo decidió, sin embargo, aun advertida en la sentencia la posibilidad de interponer recurso de casación contenciosoadministrativo $^{11}$, formular incidente de nulidad de actuaciones. Y esto como consecuencia, por un lado, de la ausencia de un precepto legal que exigiera la preparación del recurso de casación como presupuesto para declarar la nulidad y, por otro, por la falta de interés casacional objetivo que presentaba el recurso al tratarse de un asunto de valoración de la prueba. Tras la inadmisión del incidente de nulidad de actuaciones, se interponía recurso de amparo denunciando la vulneración del derecho fundamental a la tutela judicial efectiva (art. 24.1 CE), en su vertiente del derecho de acceso a los recursos. Defendía, fundamentalmente, que tras la reforma de la casación contenciosa, la exigencia del interés casacional objetivo para la formación de jurisprudencia, como único criterio de admisibilidad del recurso, «cerraba la puerta» a recursos cuyo objetivo fuera la revisión de los hechos o la valoración de la prueba al existir jurisprudencia consolidada al respecto. Interponer el recurso de casación, dada la falta de prosperabilidad del recurso, hubiera supuesto, a su juicio, un «suicido procesal». No solo se hubiera inadmitido la casación sino que además habría transcurrido el plazo para la formulación del incidente de nulidad ${ }^{12}$. Para el recurrente, la decisión del órgano judicial era irrazonable puesto que,

11 El pie de recurso señalaba que la sentencia era «susceptible de recurso de casación ante la Sala de lo Contencioso-Administrativo del Tribunal Supremo, de conformidad con lo previsto en el artículo 86.1 de la Ley reguladora de la Jurisdicción ContenciosoAdministrativa siempre y cuando el asunto presente interés casacional según lo dispuesto en el artículo 88 de la citada ley».

12 Art. 241 LOPJ: «1. No se admitirán con carácter general incidentes de nulidad de actuaciones. Sin embargo, excepcionalmente, quienes sean parte legítima o hubieran debido serlo podrán pedir por escrito que se declare la nulidad de actuaciones fundada en cualquier vulneración de un derecho fundamental de los referidos en el artículo 53.2 de la Constitución, siempre que no haya podido denunciarse antes de recaer resolución que ponga fin al proceso y siempre que dicha resolución no sea susceptible de recurso ordinario ni extraordinario». 
en su caso, el recurso no tenía ninguna posibilidad de ser admitido como consecuencia de su falta de interés casacional.

La Sección Primera decidió inadmitir el recurso de amparo. Y lo hizo mediante auto y no por providencia, como es lo usual ${ }^{13}$, por la especial trascendencia constitucional que la cuestión suscitaba ${ }^{14}$. No se encontró "causa alguna» que llevara a considerar que la decisión sobre la desestimación del incidente por mostrarse procedente el recurso de casación incurriera en arbitrariedad, manifiesta irrazonabilidad o error fáctico patente. Para la Sección, que fuera necesario que la resolución impugnada no fuera «susceptible de recurso ordinario ni extraordinario" antes de acudir al incidente de nulidad de actuaciones, se consideró «una conclusión racional y lógica» que «se basa en presupuestos certeros» ${ }^{15}$. Es más, precisó que el razonamiento del recurrente no podía ser asumido porque solo el Tribunal de casación es el que tiene competencia para decidir acerca de la existencia o no del «interés casacional» del asunto. Textualmente se afirma: «Si todo el sistema se basa [...] en el amplio margen de apreciación del Tribunal de casación sobre la concurrencia o no del interés casacional, nadie puede suplantarle y, por tanto, no pueden arrogarse los interesados, ni otros órganos judiciales, esa atribución» ${ }^{16}$. Y dice algo más que la Sección entiende que abunda en la razonabilidad de su interpretación: la apreciación de un "claro paralelismo" entre contenido del art. 88.2 y 3 LJCA, al definir los supuestos de interés casacional objetivo, con

13 El art. 50.1 CE establece que: «El recurso de amparo debe ser objeto de una decisión de admisión a trámite» y que «La Sección, por unanimidad de sus miembros, acordará mediante providencia la admisión».

14 Para la Sección, la trascendencia del recurso de amparo radicaba en que el recurso «suscita una cuestión jurídica de relevante y general repercusión desde la perspectiva del derecho a la tutela judicial efectiva, en su vertiente de acceso al recurso (art. 24.1 $\mathrm{CE})$ relacionada con el correcto cauce de agotamiento de la vía judicial previa al recurso de amparo, a partir de la última reforma operada en el recurso de casación contencioso-administrativa». Y por esto, añade, «desde la perspectiva que incumbe a este Tribunal, de interpretación de los requisitos necesarios para acudir al recurso de amparo y de preservación de la subsidiariedad de este último, estamos ante una cuestión que, en tanto no sea explícitamente resuelta, tiene un alcance general».

15 FJ 5.

16 Ibid. Advertía, también, que, tras la Ley Orgánica 7/2015, se admite la invocación de infracciones procesales junto con las sustantivas en el recurso de casación (art. 88.1 LJCA), incluyéndose "como supuestos de posible interés casacional, entre otros, la errónea interpretación o aplicación de doctrina constitucional [art. 88.2 e) LJCA] y las resoluciones dictadas en el procedimiento especial de protección de derechos fundamentales [art. 88.2 i) LJCA]» (FJ 5). 
la doctrina del Tribunal sobre la especial trascendencia constitucional fijada en el fundamento jurídico 2 de la STC 155/2009; lo que le lleva a concluir que "en principio, no es fácil que esta pueda concurrir si el debate no presenta previamente interés casacional».

El auto confirma, por tanto, desde el canon de la motivación de las resoluciones judiciales (art. 24.1 CE), es decir, tras realizar un juicio externo sobre la motivación esgrimida por el órgano judicial, que la decisión sobre la desestimación del incidente por mostrarse procedente el recurso de casación no incurría en arbitrariedad, manifiesta irrazonabilidad o error fáctico patente. Pero, una vez realizado dicho pronunciamiento, la Sección hace una afirmación más, de gran calado: declara la necesidad de la interposición de la casación contencioso-administrativa como requisito previo al planteamiento del recurso de amparo, con el argumento de que al Tribunal Supremo corresponde "exclusivamente» la apreciación del interés casacional objetivo. En concreto, se afirma que "es lógico entender que el agotamiento de la vía judicial previa al recurso de amparo exige haber intentado el recurso de casación cuando su admisibilidad dependa exclusivamente de la apreciación del interés casacional objetivo, que únicamente al Tribunal Supremo corresponde» ${ }^{17}$. Sin embargo, la primera de las declaraciones - considerar que la decisión del órgano judicial de inadmitir el incidente de nulidad de actuaciones no se muestra arbitraria, irrazonable o incursa en un error patente- no conduce necesariamente a la segunda. La Sección, no obstante, convierte el criterio seguido por el órgano judicial en criterio propio a efectos de agotamiento de la vía judicial previa respecto del posible planteamiento de un recurso de amparo y, además, parece hacerlo con carácter general. Es posible que con la mirada puesta en lo que se dijo en el Auto de la Sala Tercera del Tribunal Supremo de 11 de diciembre de 2017.

\section{SOBRE LA DECISIÓN DE LA NECESIDAD DE LA INTERPOSICIÓN DEL RECURSO DE CASACIÓN CONTENCIOSO-ADMINISTRATIVO ANTES DE ACUDIR AL AMPARO CONSTITUCIONAL}

\subsection{Tribunal Supremo y agotamiento de la vía}

En el Auto de 11 de diciembre de $2017^{18}$ se afirmó por la Sección Primera de la Sala Tercera, en contestación a un recurso de casación interpuesto en el que se denunciaba la incongruencia «interna» $\mathrm{y}$ «extrapetita» de la

17 FJ 5.

18 Sala de lo Contencioso-Administrativo, Sección 1a, RC 3711/2017. 
sentencia impugnada, que «la clara apertura del recurso de casación a resoluciones que antes lo tenían vedado excluye la inmediata y previa interposición del incidente de nulidad de actuaciones» ${ }^{19}$. Y así, como principio general, se señaló que «sólo cuando se haya decidido la inadmisión del recurso de casación se podrá afirmar que contra la resolución judicial impugnada no cabe recurso ordinario, ni extraordinario, lo que es claramente novedoso, pues en la regulación precedente la propia resolución dictada definía intrínsecamente su recurribilidad». En definitiva, para la Sección, «la condición de "inimpugnabilidad" de la resolución de instancia sólo tiene lugar cuando la declaración de inadmisión del recurso de casación por el Tribunal Supremo se produce, no cuando aquélla es dictada». O lo que es lo mismo, para el citado órgano judicial, solo cuando es inadmitido el recurso de casación la sentencia impugnada ya no es susceptible de recurso alguno, ordinario o extraordinario, y, por tanto, es válida la formulación del incidente de nulidad de actuaciones (art. 241 LOPJ).

La Sección, con dichas afirmaciones, parece convertir la interposición de la casación en un trámite obligado para poder acceder al incidente de nulidad de actuaciones y ulteriormente recurrir en amparo al Tribunal Constitucional ${ }^{20}$. Quizás, podrían haberse visto matizadas posteriormente, pues se ha de tener en cuenta que se realizaron al analizar el alcance temporal que el pronunciamiento de inadmisión por falta de interés casacional tenía a los efectos de la eventual interposición del incidente de nulidad de actuaciones, y posibilitar, en su caso, la modificación del fallo de la sentencia impugnada. En este contexto, no parecía quedar claro si se trataba de configurar una obligación general de planteamiento previo de la casación o más bien de dar la oportunidad a la parte, tras la inadmisión de la casación, de acudir al incidente de nulidad con la finalidad de remediar una lesión sin interés casacional objetivo, como lo era la incongruencia denunciada ${ }^{21}$. Dicho auto se ha visto confirmado a la luz de lo dispuesto en el ATC 65/2018 22 .

Con la interpretación de la obligatoriedad del planteamiento del recurso de casación, no exenta de polémica doctrinal, se fuerza al recurrente a plantear

19 FJ 5.3.

20 Veremos, sin embargo, que, en la STC 112/2019, el TC, tras ser inadmitido el recurso de casación por falta de interés casacional, dejará en manos del recurrente la decisión de formular o no el incidente de nulidad de actuaciones.

21 Cancer Minchot (2018: 259) cree «en una primera aproximación y a falta de más doctrina, que el TS ha simplificado, con acierto, la cuestión, convirtiendo [la] solución en "principio general"».

22 Véase STS 374/2021, de 28 de enero (Sección Segunda), y las allí citadas, que hace suya la interpretación del ATC 65/2018. 
un recurso cuya admisión es «francamente difícil»" (Alonso Murillo, 2016: 46). Al igual que el amparo, la casación contencioso-administrativa es un recurso extraordinario cuya admisión queda sometida al criterio de la Sala Tercera; de la que se ha dicho "goza de un margen de apreciación prácticamente absoluto" (Fernández Farreres, 2015: 110) o "ciertamente amplio» (Huelin Martínez de Velasco, 2017: 10). Un recurso, además, costoso para el recurrente, y tras el cual deberá formular un incidente de nulidad de actuaciones que resuelve el mismo órgano judicial al que se le imputa la vulneración de su derecho. Se ha puesto de manifiesto que agotar la vía se convierte en una «carga titánica que se traduce en una disminución de las garantías procesales, en concreto, de acceso al recurso de amparo» (Pérez Estrada, 2019: 28). Es por ello que se ha entendido «necesario que se excluya al recurso de casación como medio procedente a agotar, dada la falta de previsibilidad en su admisión", para la interposición de determinados recursos (Álvarez Menéndez, 2019: 11), o se ha estimado preferible que se dejase al perjudicado optar en la instancia «entre el incidente de nulidad de actuaciones (renunciando a la casación), o la casación (renunciando al incidente de nulidad contra el auto o sentencia de instancia)» (Cancer Minchot, 2018: 262).

La propia Sala Tercera admitía, en el Auto de 1 de marzo de $2017^{24}$, que sería difícil que por ser abundante y reiterada la jurisprudencia existente, tanto del Tribunal Constitucional como del Tribunal Supremo, se hicieran necesarios nuevos pronunciamientos en relación con denuncias por incongruencia omisiva, «salvo en aquellos supuestos en los que la omisión se refiera precisamente a una pretensión de fondo que presente dicho interés objetivo para la formación de la jurisprudencia y se invoquen como infringidos, por su inaplicación, los preceptos que la disciplinan». Y, por ello, consideró que, para evitar el «tortuoso camino procesal» que supondría agotar la vía judicial previa para llegar al amparo, antes de quejarse en casación de la incongruencia omisiva de la sentencia (art. 24.1 CE), resultaba legítimo exigir al recurrente que acreditara, como presupuesto de procedibilidad, haber instado, previamente y sin éxito, el complemento de la sentencia por el cauce previsto en los arts. 267.5 LOPJ y 215.2 LEC. La Sala considera

23 Razquin Lizarraga (2017: 199) pone de manifiesto que, «en comparación con el modelo anterior, se ha producido una drástica reducción del número de recursos admitidos. Más aún, pese al ámbito universal del recurso, no se ha producido un incremento sustancial del número de recursos de casación preparados como había pronosticado la doctrina, lo que pudiera obedecer a la dificultad de satisfacer el requisito del art. 89.2.f) LJCA».

24 ATS 1450/2017, FJ 4.3. 
que ello «refuerza los derechos procesales de los litigantes y redunda en una mayor agilidad y eficacia del trámite procesal de admisión de los recursos de casación preparados» ${ }^{25}$.

Como se ha señalado por la doctrina, «[e]l nuevo sistema tiene dos claves que se reconcilian mal o que son contradictorias entre sí: excesivo rigor o trabajo al recurrente, por una parte, y, por otra parte, discrecionalidad o incertidumbre o incluso azar en el momento de la admisión del recurso» (González-Varas Ibáñez, 2016: 78). Pero es que, además, si con la reforma del recurso de casación contencioso-administrativo lo que se pretendía era intensificar las garantías en la protección de los derechos de los ciudadanos, reforzándolo como instrumento por excelencia para asegurar la uniformidad en la aplicación judicial del derecho, y no convertir a la Sala Tercera en una tercera instancia, sino que cumpliera con su función nomofiláctica, parece que la obligación general de plantear la casación con carácter previo al incidente y al amparo desactiva dichos efectos. La obligatoriedad de la interposición del recurso de casación para llegar a la protección efectiva de los derechos supuestamente vulnerados somete al recurrente no solo a un complicado itinerario procesal, sino que además obliga a la Sala al estudio de todos los asuntos susceptibles de casación, es decir, de todas las sentencias dictadas en la jurisdicción contencioso-administrativa en cualquier instancia, para determinar en cada caso si cuentan o no con el necesario «interés casacional objetivo».

Si lo que se pretendía con la reforma era limitar el conocimiento de recursos de casación y reducir la carga de trabajo de la Sala Tercera del Tribunal Supremo - finalidad existente también en las anteriores reformas operadas en el recurso de casación contencioso-administrativo (Pérez Estrada, 2019: 5)—, parece paradójico obligar con carácter general a plantear un recurso a los solos descartar el interés casacional para la formación de jurisprudencia, como paso previo al de la formulación del incidente de nulidad y posterior amparo (en el mismo sentido, Álvarez Menéndez, 2019: 11). En relación con el amparo objetivo consideré que: «Admitir, por un lado, que la finalidad de la reforma era la descongestión de trabajo a través de la limitación del conocimiento de aquellos recursos que contaran con especial trascendencia constitucional y, a la vez, obligar al recurrente a acudir al TC para, tras una decisión sobre la misma, recurrir finalmente al TEDH», aun cuando estimara que su recurso no contaba con la especial trascendencia constitucional requerida, se mostraba «contradictorio» (García Couso, 2016: 124).

25 FJ 4.5 . 


\subsection{Tribunal Constitucional y Tribunal Europeo de Derechos Humanos}

Las cuestiones procesales relativas al acceso a la casación así como la apreciación del interés casacional objetivo para la formación de jurisprudencia, son temas que compete dilucidar a la Sala de lo Contencioso-administrativo del Tribunal Supremo ${ }^{26}$. Distinto es si el Tribunal Constitucional, en el ejercicio de su competencia, puede decidir, a efectos del cumplimiento del agotamiento de la vía judicial previa al amparo, sobre la necesidad o no del planteamiento del recurso de casación objetivo. Hasta el momento, la decisión adoptada por la Sección Primera -ATC 65/2018 - no se ha visto ratificada por sentencia, y habría argumentos para entender que su interposición no tiene por qué estimarse obligatoria en aquellos asuntos en los que el demandante de amparo pudiera argumentar que el recurso de casación no se mostraba como un recurso útil o efectivo. Considerar, en definitiva, la casación como un recurso procedente pero no necesario para agotar la vía judicial previa al amparo, según los casos.

Por ejemplo, en el Auto de 2 de abril de $2018^{27}$, la Sala Tercera decidió la inadmisión de un recurso de casación al quedar desprovisto, si bien de forma sobrevenida, de cualquier interés casacional objetivo para la formación de jurisprudencia (art. 88.1 LJCA); y ello por versar sobre cuestiones que ya contaban con una doctrina jurisprudencial consolidada en numerosas sentencias dictadas en sentido contrario al pretendido por la parte recurrente en relación con otros recursos también formulados por ella. ¿A partir de ese momento sería razonable exigir el planteamiento del recurso de casación previo al amparo en otros asuntos idénticos?

No es el único caso. Por ejemplo, se ha advertido también que la controversia sobre los aspectos fácticos del pleito no tiene encaje posible en ningún supuesto de interés casacional porque carece por definición de la dimensión de «interés casacional», que es inherente a este recurso extraordinario ${ }^{28}$.

26 Como se ha afirmado reiteradamente por el TC, «la interpretación y aplicación de las normas procesales que contemplan los requisitos para la admisión de los recursos son materias de legalidad ordinaria, propias de los tribunales de Justicia (art. 117.3 CE), de modo que el control de las resoluciones judiciales de inadmisión de los recursos por parte de la jurisdicción constitucional «es meramente externo" [...] evitando toda ponderación acerca de la corrección jurídica de las mismas»(STC 166/2020, de 16 de noviembre, FJ 2).

27 RC 1772/2017.

28 ATS de 10 de abril de 2017 (RC 227/2017). En el ATS de 5 de diciembre de 2017 (RQ 269/2017) se ha afirmado que "con arreglo al artículo 87 Bis 1 LJCA, el recurso de casación se reserva a cuestiones jurídicas, centrando su objetivo en la interpretación 
$\mathrm{O}$ que han de quedar excluidas las cuestiones en las que la parte pone de manifiesto su discrepancia con el resultado valorativo de la prueba realizado por el tribunal $a q u o^{29}$. Asimismo se ha afirmado que «son ajenas a la finalidad del nuevo recurso de casación las controversias que se reducen a cuestiones puramente casuísticas y singularizadas, carentes como tales de una dimensión hermenéutica del Ordenamiento que permita apreciar su proyección o repercusión, al menos potencial, sobre otros posibles asuntos» ${ }^{30}$. ¿Podría el Tribunal Constitucional, en el ejercicio de su competencia, optar por entender agotada la vía tras haberse planteado un incidente de nulidad de actuaciones por no mostrarse el recurso de casación un recurso procedente y útil al no contar con el necesario «interés casacional objetivo»?

Estimé, tras la aprobación de la Ley Orgánica 7/2007, que, dada la jurisprudencia del Tribunal Europeo de Derecho Humanos (TEDH), era posible que no se presentara necesario recurrir ante el Tribunal Constitucional a efectos de entender agotada la vía nacional previa a la interposición de un recurso ante el Tribunal europeo, de considerar la parte que su recurso no contaba con la necesaria «especial trascendencia constitucional» (García Couso, 2010: 159; en el mismo sentido, Pérez de los Cobos Orihuel, 2017: 13). La jurisdicción constitucional había dejado de ser, tras la reforma del amparo de 2007, "una jurisdicción obligatoria para convertirse en voluntaria, a la que acude el particular si considera que su recurso cumple con la requerida especial trascendencia constitucional» (García Couso, 2016: 125). En este sentido, se ha sostenido por la doctrina que, a efectos de agotamiento de la vía judicial previa al acceso al TEDH, la interposición del recurso de amparo no debiera considerarse como un remedio necesario, pero tampoco improcedente (Aragón Reyes, 2015: 241). Creo que también, en este caso, la decisión sobre el planteamiento del recurso de casación contencioso-administrativo previo al amparo debería corresponder al recurrente (en este sentido, Cancer Minchot, 2018: 259), que no solo se verá obligado a justificar el interés casacional objetivo de su recurso ${ }^{31}$, aun cuando se encuentre convencido de

del Derecho y no en los asuntos o cuestiones con perfiles marcadamente casuísticos y circunstanciados, precisamente porque estos últimos carecen de la dimensión de interés casacional objetivo que es inherente al nuevo sistema casacional» (FJ 4).

29 ATS de 19 de junio de 2017 (RQ 273/2017). Puede verse también ATS de 26 de septiembre de (RQ 238/2018).

30 ATS de 26 de septiembre de 2018 (RQ 238/2018), FJ 2.

31 En relación con el recurso extraordinario por infracción procesal civil, el TC, en la STC 143/2020, de 19 de octubre, ha afirmado que "tratándose del acceso por interés casacional, el órgano judicial no puede sustituir a la parte interesada, dando por hecho que la resolución por él dictada infringe jurisprudencia del Tribunal Supremo (lo que 
que no existe, sino que incluso se verá penalizado con la imposición de las costas tras la decisión de inadmisión por él esperada ${ }^{32}$ (Cancer Minchot, 2018: 259 y Casado Casado, 2020: 128). Imposición que encontraría más sentido de plantearse un recurso de casación sin que el asunto presentara el necesario interés casacional objetivo para la formación de jurisprudencia.

$\mathrm{El} \mathrm{TEDH}$ ha estimado como recursos utilizables ante las jurisdicciones internas competentes a efectos de entender agotada la vía interna aquellos que se muestren «accesibles, eficaces y no discrecionales», correspondiéndole determinar la naturaleza interna de la jurisdicción en función de factores como la naturaleza jurídica del recurso, el instrumento que ha previsto su creación, su competencia y la incardinación en el sistema judicial existente ${ }^{33}$. Para el citado Tribunal, la previsión de la vía de recurso debe estar clara y suficientemente consolidada en la práctica del ordenamiento interno ${ }^{34}$. Al recurrente no se le exige que formule recursos discrecionales o extraordinarios, de inviabilidad probable o ineficaces e inadecuados, es decir, que no sirvan para reparar la lesión producida ${ }^{35}$. Además, para el caso de que existan varias vías de recurso posible, no se considera necesario que las practique todas, sino que basta con que siga aquella que considere más efectiva; tendiendo el Tribunal a interpretar el requisito del agotamiento de los recursos internos a su favor cuando su eficacia comparativa no es obvia ${ }^{36}$. Es al Estado al que corresponde acreditar, en su caso, la existencia de una vía de recurso interna, eficaz y accesible que el recurrente ha obviado.

obligaría a precisar cuál sería esa), o que ha resuelto puntos o cuestiones donde existe efectivamente jurisprudencia contradictoria de las audiencias provinciales (tendría entonces que decir no solo cuál es esa doctrina, sino superar el requisito exigido jurisprudencialmente de identificar dos resoluciones de distintas secciones, que defiendan los criterios opuestos) o, en fin, que ha habido una infracción (y cuál) de una norma que no lleva más de cinco años en vigor» [FJ 5 c)].

32 Art. 90.8 LJCA: «La inadmisión a trámite del recurso de casación comportará la imposición de las costas a la parte recurrente, pudiendo tal imposición ser limitada a una parte de ellas o hasta una cifra máxima».

El art. 35.1 del Convenio de Roma, que se refiere a las condiciones de admisibilidad de las demandas presentadas ante el Tribunal de Estrasburgo, establece: "Al Tribunal no podrá recurrirse sino después de agotar las vías de recurso internas, tal como se entiende según los principios de derecho internacional generalmente reconocidos y en el plazo de seis meses a partir de la fecha de la decisión interna definitiva».

34 STEDH de 27 de abril de 2017, asunto Di Sante c Italia, $\$ 22$.

35 STEDH de 27 de febrero de 1980, asunto Deweer c. Bélgica, $\$ 48$.

36 STEDH de 20 de marzo de 2018, asunto Budayeva y otros c. Rusia, $\$ 110$. 
En relación, en concreto, con el recurso de casación y la falta de previsibilidad de su admisibilidad, el TEDH ha considerado que «un recurso de casación, que es una vía de recurso extraordinario, no accesible de pleno derecho y cuya activación se deja a discreción del Tribunal, no puede considerarse como un recurso eficaz que los recurrentes tengan que agotar ${ }^{37}$. Además, se señala que dicho recurso impone a los solicitantes «una carga desproporcionada que rompe el equilibrio justo entre la preocupación legítima de garantizar el respeto de las condiciones formales para acceder al Tribunal Constitucional y el derecho de acceso" ${ }^{38}$.

Por la doctrina se ha puesto de manifiesto que el interés casacional objetivo es «un concepto jurídico indeterminado, de carácter lábil, entregado a la estimación discrecional del TS, al que se atribuye el poder de determinar su carga de trabajo y sobre todo la virtualidad y alcance de la nueva casación contencioso-administrativa» (Razquin Lizarraga, 2017: 200). Y se ha afirmado también que «el éxito de la reforma ha tenido contrapartidas importantes y, de manera principal, la de haber sumido en la más absoluta incertidumbre la determinación de si el recurso será viable» (Fernández Farreres, 2015: 128).

Quizá la declaración general realizada por la Sección Primera sobre el necesario planteamiento previo del recurso de casación contencioso-administrativo, como forma de agotamiento de la vía judicial antes de la interposición del recurso de amparo, deba verse matizada en función del caso y la argumentación esgrimida por el demandante de amparo en su recurso. Y ello en aras de facilitarle el camino hacia una efectiva protección de los derechos fundamentales que, especialmente en la jurisdicción contencioso-administrativa, se ve mermada - pues, en la mayoría de las ocasiones son procedimientos de única instancia - al contar como únicos mecanismos de protección recursos sometidos a procesos de admisión en los que los tribunales cuentan con un amplio margen decisorio - casación y amparo-, o ante una reclamación que se hace ante el mismo órgano judicial al que se le imputa la supuesta vulneración -incidente de nulidad de actuaciones — (véase el trabajo de Casado Casado, 2020).

Se ha dicho a favor de la interpretación de la obligatoriedad de la interposición previa de la casación, que parece difícil negar la existencia de interés casacional si se estima que tiene especial trascendencia constitucional, por lo que se considera «un sinsentido» acudir al Tribunal Constitucional sin antes no haber acudido al Tribunal Supremo (Triana Reyes, 2017: 3); en la misma

37 STEDH de 12 de noviembre de 2002, caso Bélés y otros $c$. República Checa; la transcripción está extraída del trabajo de Álvarez Menéndez (2019: 9).

38

Ibid. 
línea se pronunció el ATC 65/2018 ${ }^{39}$. Pero esa no es, a mi juicio, la cuestión principal. Los supuestos de admisión en ambos casos, aunque parecidos, son distintos, y los tribunales que aprecian tanto el interés casacional objetivo como la especial trascendencia constitucional también lo son. La inadmisión por falta de interés casacional de un recurso no implica necesariamente la apreciación de la falta de especial trascendencia constitucional, y tampoco la admisión por el Tribunal Supremo comporta la admisión por el Tribunal Constitucional (en este sentido, Álvarez Menéndez, 2019: 7). En cualquier caso, también sobre este aspecto podría argumentar el demandante de amparo en su recurso.

La reflexión sobre la necesidad del planteamiento previo del recurso de casación contencioso-administrativo debería partir no de la similitud de los supuestos contemplados como de interés casacional o de especial trascendencia constitucional, sino de la naturaleza objetiva del mismo. La casación se ha objetivado y esa objetivación no puede llevar a obligar al recurrente a plantear un recurso que estima improcedente por entender que carece del requisito fundamental para su admisión, con la única razón de que el Tribunal Constitucional no puede conocer de un asunto sin que antes se haya pronunciado el Tribunal Supremo acerca de su interés casacional. La decisión de no plantear recurso de casación por la ausencia de interés casacional objetivo del asunto, supone, con la interpretación del ATC 65/2018, renunciar desde ese momento al amparo constitucional; «desincentiva la interposición del recurso de amparo" (Recuerda Girela, 2020: 428). Se debe tener presente que con la reforma se antepone la dimensión objetiva de la casación contenciosoadministrativa para la formación de jurisprudencia, a la subjetiva propia de cualquier remedio procesal, y esto debe hacer reflexionar acerca del interés que el particular puede encontrar en plantear, en primer lugar, un recurso de casación objetivo y, posteriormente, otro recurso también objetivo, el recurso

39 En el FJ 5 del auto se afirma: «Tampoco cabe olvidar que el recurso de amparo exige, tras esa reforma legal, como requisito propio, la especial trascendencia constitucional [art. 50.1 b) LOTC] y, en principio, no es fácil que esta pueda concurrir si el debate no presenta previamente interés casacional. No en vano, la comparación del contenido del artículo 88.2 y 3 LJCA, al definir los supuestos de interés casacional objetivo, con la doctrina de este Tribunal sobre la especial trascendencia constitucional - la fijada en el fundamento jurídico 2 de la STC 155/2009— permite apreciar un claro paralelismo. Ello abunda en la razonabilidad de la interpretación que aquí avalamos, en lo que a la exigencia del recurso de casación respecta como paso previo al incidente de nulidad de actuaciones». 
de amparo, previa formulación de un incidente de nulidad de actuaciones ${ }^{40}$, para encontrar finalmente la protección que le ofrece el art. 53.2 CE que establece que: "Cualquier ciudadano podrá recabar la tutela de las libertades y derechos reconocidos en el artículo 14 y la Sección primera del Capítulo segundo ante los Tribunales ordinarios por un procedimiento basado en los principios de preferencia y sumariedad y, en su caso, a través del recurso de amparo ante el Tribunal Constitucional».

\section{AGOTAMIENTO DE LA VÍA JUDICIAL PREVIA E INADMISIÓN DEL RECURSO DE CASACIÓN POR FALTA DE INTERÉS CASACIONAL: STC $112 / 2019$}

\section{ANTECEDENTES}

El recurso de amparo que dio lugar al dictado por el Pleno de la STC $112 / 2019$, de 3 de octubre, se interpuso contra la sentencia de la Sala de lo Contencioso-Administrativo del Tribunal Superior de Justicia de Murcia que declaró la inadmisibilidad del recurso contencioso-administrativo y contra la providencia de la Sección Primera de la Sala de lo Contencioso-Administrativo del Tribunal Supremo por la que se inadmitió a trámite el recurso de casación formulado por el recurrente. El recurrente aduce que la citada sentencia, al inadmitir su recurso contencioso-administrativo por apreciar que el acto impugnado no había agotado la vía administrativa previa [art. 69 c) LJCA], había vulnerado su derecho de acceso a la jurisdicción (art. 24.1 CE), ya que el acto impugnado no había sido debidamente notificado. Contra la citada sentencia se interpuso recurso de casación que fue inadmitido al apreciar que carecía de interés casacional objetivo para la formación de jurisprudencia.

\section{SOBRE EL ÓBICE PROCESAL DEL AGOTAMIENTO DE LA VÍA JUDICIAL PREVIA AL AMPARO: FALTA DE INTERÉS CASACIONAL E INCIDENTE DE NULIDAD DE ACTUACIONES}

La STC 112/2019, dictada por el Pleno del Tribunal, dedica un fundamento jurídico, en concreto el FJ 3, al estudio del agotamiento de la vía judicial en los casos en los que el recurso interpuesto contra la resolución que se estima lesiva de derechos fundamentales ha sido inadmitido por razones

40 Incidente de nulidad de actuaciones, previo al amparo, que se ha convertido en potestativo tras el dictado de la STC 112/2019. 
procesales no imputables a la falta de diligencia de la parte. Precisamente la especial trascendencia del recurso de amparo la encuentra el tribunal, no en la cuestión de fondo planteada, sino en la cuestión procesal. Su intención es aclarar o modificar su doctrina en relación con la necesidad de interponer incidente de nulidad de actuaciones para agotar la vía judicial previa al recurso de amparo cuando la vulneración del derecho fundamental no se imputa a la última resolución judicial, sino a la inmediatamente anterior, y esta vulneración ha quedado imprejuzgada tras haber sido inadmitido el recurso de casación contencioso-administrativo interpuesto por el recurrente por falta de interés casacional objetivo para la formación de jurisprudencia.

El Pleno comienza su argumentación admitiendo que la aplicación de la doctrina constitucional determinaría la inadmisión del recurso de amparo por no haber agotado la vía judicial, pues al imputarse la lesión de derechos fundamentales a la sentencia del Tribunal Superior de Justicia y haber sido inadmitido el recurso de casación interpuesto contra dicha sentencia por apreciar el Tribunal Supremo que carecía de interés casacional, hubiera debido formularse, antes del amparo, un incidente de nulidad de actuaciones contra la referida sentencia. Sin embargo, decide modificar dicha doctrina y considerar que en estos supuestos no es preciso interponer un incidente de nulidad de actuaciones para cumplir el requisito que exige agotar la vía [art. 44.1 a) LOTC].

Dicho cambio se sustenta en dos razones: por un lado, en la interpretación «flexible y finalista» desde la que el tribunal entiende que ha de enjuiciarse el requisito del agotamiento de la vía judicial antes de interponer el recurso de amparo, como así se ha sostenido jurisprudencialmente; y, por otro, en la inexistente obligación de utilizar en cada caso todos los medios de impugnación posibles, «sino tan sólo aquellos normales que, de manera clara, se manifiestan como ejercitables, de forma que no quepa duda respecto de la procedencia y la posibilidad real y efectiva de interponer el recurso».

En aplicación de dichos criterios, el tribunal considera que de la normativa procesal que regula el incidente de nulidad de actuaciones no cabe deducir que en supuestos como el examinado "proceda de manera clara su interposición", pues del art. 241 LOPJ «no se infiere que este incidente deba interponerse también en los casos en los que el recurso ordinario o extraordinario que se haya interpuesto contra la resolución que se estima lesiva de derechos fundamentales se inadmita por razones procesales que no sean imputables a la falta de diligencia de la parte» ${ }^{41}$. Igualmente aprecia que tampoco la naturaleza subsidiaria del recurso de amparo exige en estos casos su formulación, ni que la subsidiaridad del amparo puede conducir a una sucesión ilimitada de

$41 \quad$ FJ 3 d). 
recursos judiciales. Se concluye, pues, que el planteamiento del incidente de nulidad en estos supuestos no puede considerarse necesario para agotar la vía judicial previa al recurso de amparo. Frente a la resolución judicial que se estima lesiva de derechos fundamentales «se interpuso el recurso que, de acuerdo con la legislación procesal, es, en principio, procedente para obtener esa tutela —el recurso de casación- y este recurso se interpuso cumpliendo los requisitos de tiempo y forma que establece la referida normativa» ${ }^{42}$.

Dicho lo anterior, el tribunal también admite que la parte pueda formular incidente de nulidad de actuaciones, cuando concurren las circunstancias descritas, dado que tampoco puede considerarse un recurso manifiestamente improcedente, pues su improcedencia no deriva «de manera terminante, clara e inequívoca» del art. 241.1 LOPJ. Así pues, también el citado incidente puede considerarse un cauce idóneo para obtener la tutela de los derechos fundamentales que se imputan a la resolución frente a la que se interpuso el recurso de casación inadmitido. El incidente de nulidad de actuaciones no se considera un remedio procesal necesario a afectos del agotamiento de la vía, pero tampoco manifiestamente improcedente. Con esta decisión, el Tribunal entiende que garantiza la tutela judicial frente a las vulneraciones de derechos fundamentales que ocasionen los órganos judiciales cuando sus decisiones no son susceptibles de recurso (arts. 24.1 y 53.2 CE). Razona que, en estos casos, es preciso establecer un cauce procesal en la vía judicial, pues, tras la reforma operada en el recurso de amparo por Ley Orgánica 7/2007, la tutela por el Tribunal Constitucional solo procederá en los supuestos excepcionales en los que la cuestión planteada en el recurso tenga especial trascendencia constitucional. Por ello, si la frustración del recurso no es consecuencia de la defectuosa actuación procesal de la parte, el recurrente podrá obtener la tutela de los derechos fundamentales que hizo valer a través del recurso intentado, instando un incidente de nulidad de actuaciones ante el órgano judicial que dictó la resolución que se estima los vulneró.

De lo dicho cabe extraer las siguientes conclusiones.

En primer lugar, que el recurso de casación es, en principio, un recurso procedente, si bien el Pleno no realiza ningún juicio sobre la obligatoriedad de su planteamiento previo a la interposición del recurso de amparo. Excede del caso, pues el pronunciamiento se centraba en dilucidar si es necesario para entender agotada la vía judicial, la formulación del incidente de nulidad frente a la resolución objeto del recurso de casación inadmitido por falta de interés casacional. Así pues, hasta al momento no hay otro pronunciamiento que el realizado por la Sección Primera (ATC 65/2018).

42 Ibid. 
En segundo lugar, que la inadmisión del recurso de casación por carecer de interés casacional objetivo para la formación de jurisprudencia, no puede ser considerado como un defectuoso agotamiento de la vía imputable a la falta de diligencia de la parte. Sobre esta cuestión no se argumenta en la sentencia. Se parte de dicha consideración. Pero parece obvio que dicha decisión deriva del alto margen de apreciación que sobre la decisión de admisión del recurso de casación contencioso-administrativo tiene la Sala Tercera ${ }^{43}$.

En tercer lugar, que, en la línea del TEDH, el Tribunal Constitucional no considera necesario que el demandante practique todas las vías de impugnación necesarias, solo aquella que considere efectiva ${ }^{44}$. Deja en manos del demandante de amparo la estrategia procesal a seguir, y decidir si formular o no, tras la inadmisión de la casación por falta de interés casacional, el incidente de nulidad de actuaciones. No es necesario que «se apuren las posibilidades que los cauces procesales ofrecen en la vía judicial para la reparación del derecho fundamental que se estima lesionado ${ }^{45}$.

Y por último, y como consecuencia, una vez más, del carácter «discrecional» tanto de la decisión de la admisión del recurso de casación como la del recurso de amparo, el tribunal reconoce que el planteamiento posterior del incidente de nulidad de actuaciones, tras la inadmisión del recurso de casación por falta de interés casacional, será procedente, aunque no necesario, a afectos del agotamiento de la vía, con el fin de poder evitar que el recurrente, si así lo estima pertinente, no se quede sin obtener la correspondiente tutela judicial subjetiva de los derechos invocados en la vía judicial.

Tanto por lo afirmado como por lo omitido en la sentencia, se deduce que el Tribunal ha tomado su decisión a mi juicio acertada, partiendo principalmente de la naturaleza objetiva de ambos recursos — contenciosoadministrativo y amparo- y del importante margen de apreciación que caracteriza las decisiones sobre su admisión. Ante el «tortuoso» itinerario procesal, se intenta flexibilizar el requisito del agotamiento de la vía judicial con la finalidad de facilitar no solo el camino del recurrente hacia el amparo constitucional, sino también la posibilidad de protección de sus derechos fundamentales a través del incidente de nulidad de actuaciones en la juris-

43 También el TEDH ha conocido de asuntos tras haber sido previamente inadmitido el recurso de amparo por carecer de especial trascendencia constitucional (SSTEDH de 3 de abril de 2012, asunto Manzanas Martín c. España; de 29 de marzo de 2016, Gómez Almeda c. España, y de 16 de julio de 2016, Flores Quirós c. España).

44 STEDH de 20 de marzo de 2018, asunto Budayeva y otros c. Rusia, $\$ 110$.

45 SSTC 133/2001, de 13 de junio, FJ 3; 36/2004, de 8 de marzo, FJ 2; 288/2005, de 7 de noviembre, FJ 1 y 144/2007, de 18 de junio, FJ 2. 
dicción ordinaria. Y lo hace al reconocer (i) que la inadmisión del recurso de casación por falta de interés casacional objetivo no se puede imputar a la falta de diligencia de la parte; (ii) que es suficiente, en tal caso, haber intentado un recurso procedente, y no todos los utilizables; (iii) que de ser promovido aquel que no se considera necesario - en este caso, el incidente de nulidad de actuaciones - tampoco se estimará que con ello se ha prolongado artificialmente la vía, y (iv) que no es necesario un pronunciamiento de fondo sobre la cuestión planteada para entender agotada la vía judicial previa al amparo, sino tan solo haber intentado el remedio procesal pertinente para entender cumplido el principio de subsidiariedad que informa el recurso de amparo.

\section{AGOTAMIENTO DE LA VÍA JUDICIAL PREVIA E INADMISIÓN DEL RECURSO DE CASACIÓN POR INSUFICIENTE JUSTIFICACIÓN DEL INTERÉS CASACIONAL: STC 121/2019}

\section{POSICIÓN DEL TRIBUNAL CONSTITUCIONAL}

Como se ha visto en el apartado anterior, el Tribunal ha optado, en la STC 112/2019, por considerar que la inadmisión del recurso de casación por la «falta de interés casacional objetivo» no es una inadmisión por razones procesales imputable a la falta de diligencia de la parte. La aplicación de la doctrina sentada en la citada sentencia ha llevado al Tribunal a apreciarlo, también, en casos en los que la inadmisión se ha decidido por «insuficiente justificación del interés casacional ${ }^{46}$. Como ya se ha señalado en líneas anteriores, la inadmisión del recurso de amparo por falta de agotamiento de la vía judicial puede producirse no solo por la falta de un recurso, sino también porque este haya sido interpuesto de forma defectuosa, bien desde el punto de vista temporal por ejercicio extemporáneo del mismo o por una cuestión formal.

En la primera de las sentencias en las que el Tribunal se ha pronunciado al respecto -STC 121/2019, de 28 de octubre- se dilucidaba un asunto en el que la federación recurrente interpuso recurso de casación frente a la resolución judicial que consideraba lesiva de su derecho fundamental. La Sala de lo Contencioso-Administrativo del Tribunal Superior de Justicia de

46 Se ha de distinguir entre los supuestos de inadmisión del recurso de casación contencioso-administrativo por falta de interés casacional, por falta de justificación del interés casacional y por insuficiente justificación del interés casacional. También el TC ha distinguido dichos supuestos: falta de especial trascendencia constitucional y falta o insuficiencia de la justificación. 
Andalucía (sede de Sevilla) tuvo por preparado dicho recurso. Sin embargo, la Sección Primera de la Sala de lo Contencioso-Administrativo del Tribunal Supremo acordó, posteriormente, la inadmisión a trámite del recurso, ex art. 90.4 d) LJCA, por estimar que el escrito de preparación no cumplía con la exigencia que establece el art. 89.2 f) LJCA de justificar debidamente el interés casacional objetivo $^{47}$. La Sala Primera del Tribunal Constitucional consideró, en su FJ 2, que las diferencias en la apreciación respecto del cumplimiento de los requisitos establecidos en el art. 89.2 LJCA, eran razón suficiente para no poder concluir que la inadmisión de dicho recurso de casación podía ser imputable «de forma clara e inequívoca» a la falta de diligencia de la recurrente.

También se ha considerado así en la STC 8/2020, de 27 de enero, en la que se afirmó que dado que la sala de instancia tuvo por preparado el recurso de casación, mientras que el Tribunal Supremo consideró que dicho escrito contenía una justificación insuficiente - que no inexistente- de un interés casacional objetivo, no era "posible estimar que la inadmisión del recurso de casación obedeciera a un defecto procesal manifiesto e incontrovertible o, dicho de otro modo, fuera atribuible de forma clara e inequívoca a la falta de diligencia de la parte, razón por la que procede considerar debidamente agotada la vía judicial previa al recurso de amparo» ${ }^{48}$.

Con posterioridad, y haciendo referencia a la STC 8/2020, se dicta la STC 166/2020, de 16 de noviembre, que, en su FJ 2 c), señala, igualmente, «que no cabe apreciar la falta de agotamiento en aquellos supuestos en los que el recurso resulta frustrado por no contener los escritos de preparación o interposición una fundamentación suficiente o adecuada de algún extremo que, como requisito procesal de acceso al recurso, previenen las normas procesales». Y razona que no es lo mismo "prescindir lisa y llanamente de la correspondiente justificación que exponerla en forma infundada», como tampoco "es jurídicamente indiferente el carácter grosero o simplemente discutible del carácter infundado de la justificación ofrecida».

En definitiva, la inadmisión del recurso de casación por "falta de justificación» del interés casacional —que es diferente a la «falta de interés casacional»— convertirá la interposición del citado recurso en una interposición defectuosa atribuible a la falta de diligencia de la parte, lo que conllevará

47 El art. 89.2 f) LJCA exige, en el escrito de preparación del recurso de casación, «fundamentar con singular referencia al caso, que concurren alguno o algunos de los supuestos que, con arreglo a los apartados 2 y 3 del artículo anterior, permiten apreciar el interés casacional objetivo y la conveniencia de un pronunciamiento de la Sala de lo Contencioso-administrativo del Tribunal Supremo».

48

FJ 2. 
la inadmisión del recurso de amparo. No así en los casos en los que la justificación se muestre insuficiente o inadecuada y dicho defecto procesal no fuera atribuible de forma clara e inequívoca a la falta de diligencia del recurrente.

\section{POSICIÓN DEL TRIBUNAL EUROPEO DE DERECHOS HUMANOS EN RELACIÓN CON EL RECURSO DE AMPARO}

En la STEDH Arribas Antón c. España, de 20 de enero de 2015, dictada a consecuencia de un recurso planteado contra una providencia de inadmisión de un amparo constitucional por falta del requisito procesal de la justificación de la especial trascendencia constitucional ${ }^{49}$, el Tribunal Europeo, tras contestar a la queja expuesta y advertir de la no vulneración del Convenio, quiso hacer «hincapié en subrayar que el hecho de que el Tribunal Constitucional haya declarado inadmisible un recurso de amparo aduciendo que no revestía la especial trascendencia constitucional requerida o, en su caso, que el recurrente no había acreditado la existencia de tal trascendencia», no le impedía pronunciarse sobre la admisibilidad y el fondo de una demanda ( $\$$ $51)^{50}$

Más recientemente, sin embargo, el TEDH ha inadmitido recursos interpuestos por no haber agotado correctamente los recursos nacionales al haber sido previamente inadmitido el recurso de amparo por no cumplir con la obligación de justificar la especial trascendencia constitucional de su recurso (art. 49.1 LOTC) (Decisión de 22 de octubre de 2020, asunto Álvarez Juan c. España) o por mostrarse insuficiente la justificación de la especial transcendencia constitucional ofrecida (Decisión de 17 de diciembre de 2020, asunto Morales Rodríguez y Vázquez Moreno c. España).

49 El recurso ante el TEDH se interpuso por considerar que el requisito de la justificación de la especial trascendencia constitucional vulneraba su derecho a la tutela judicial efectiva (arts. 6.1 y $13 \mathrm{CEDH}$ ) por su naturaleza excesivamente formal.

Previamente, el TEDH ya había conocido de vulneraciones alegadas —entre otras, STEDH Río Prada c. España, de 21 de octubre de 2013-, tras haberse inadmitido el recurso de amparo por falta de justificación de la especial trascendencia constitucional, pero no se había pronunciado sobre ello explícitamente. Posteriormente conoció de otros recursos también tras ser inadmitidos previamente los amparos por falta o insuficiente justificación de la especial trascendencia constitucional: SSTEDH Rodríguez Ravelo c. España, de 12 de enero de 2016; y Pérez Martínez c. España, de 23 de febrero de 2016; Laguna Guzmán c. España, de 6 de octubre de 2020; asunto Saquetti Iglesias c. España, de 30 de junio de 2020; asunto Sabre y Boughassal c. España, de 18 de diciembre de 2018, y Haddad c. España, de 18 de junio de 2019. 
En la Decisión Álvarez Juan c. España, el TEDH recuerda que el hecho de que el Tribunal Constitucional haya declarado inadmisible un recurso de amparo por la falta de la especial trascendencia constitucional requerida, no impide que se pronuncie sobre la admisibilidad y el fondo de un recurso que se le haya presentado, pero que no ocurre lo mismo cuando el recurrente no cumple con la carga de justificar la especial trascendencia constitucional del recurso de amparo, ya que considera que es consecuencia de la falta de diligencia de la parte recurrente. Motivo por el cual el recurso deberá ser inadmitido por no haber agotado los recursos internos, al no haberse dado al Tribunal Constitucional la oportunidad de prevenir o remediar las violaciones del Convenio.

Posteriormente, en la Decisión Morales Rodríguez y Vázquez Moreno c. España, el citado Tribunal hace, a mi juicio, una matización importante respecto de la inadmisión del recurso de amparo por «insuficiente justificación de la especial trascendencia constitucional», al advertir que si bien no le corresponde sustituir al Tribunal Constitucional de un Estado miembro en la evaluación de las condiciones de admisibilidad de un recurso, sí que le incumbe verificar la evaluación realizada por si fuera tan formalista como para restringir el acceso a un recurso efectivo. Así pues, la inadmisión por insuficiente justificación de la especial trascendencia constitucional, a diferencia de la inadmisión por su falta de justificación, no se convierte por sí misma en razón de inadmisión del recurso presentado. En este caso, el Tribunal inadmite el recurso por apreciar que los demandantes no llevaron a cabo una verdadera justificación acerca de por qué su caso requería una decisión sobre el fondo por parte del Tribunal Constitucional, pues en el epígrafe formal de la demanda de amparo dedicado a la justificación de la especial trascendencia constitucional se limitaron a enumerar determinados casos en abstracto sin establecer ninguna conexión y sin hacer esfuerzo intelectual alguno para cumplir con la citada condición procesal.

\section{A MODO DE CONCLUSIÓN}

En las sentencias objeto de este estudio, el Tribunal Constitucional ha seguido una línea «flexible y finalista» al enjuiciar el requisito del agotamiento de la vía judicial previa al amparo en relación con el planteamiento del recurso de casación contencioso-administrativo. Dicho requisito procesal ha de ser analizado, a mi juicio, desde la consideración de la nueva naturaleza objetiva de la casación y del amplio margen de apreciación que la ley concede a la Sala Tercera del Tribunal Supremo sobre la decisión de su admisión. Desde esta perspectiva, no se podía sino apreciar, como así lo ha hecho el Pleno, que la 
inadmisión del recurso de casación por falta de interés casacional objetivo para la formación de jurisprudencia no puede ser imputable a la falta de diligencia de la parte. E, igualmente, dada la naturaleza objetiva del recurso de amparo, considerar el incidente de nulidad de actuaciones formulado frente a la resolución contra la que se interpuso el recurso de casación inadmitido, como un remedio procesal procedente pero no necesario, a los efectos del agotamiento de la vía judicial previa.

No ha sido esta, sin embargo, la línea seguida en el ATC 65/2018. Quizás, tras la jurisprudencia posterior, la declaración realizada por la Sección Primera sobre el necesario planteamiento del recurso de casación contencioso-administrativo previo al amparo, pueda verse matizada en función del caso y la argumentación esgrimida por el demandante de amparo.

\section{Bibliografía}

Alonso Murillo, F. (2016). El nuevo recurso de casación contencioso-administrativo en materia tributaria. Madrid: AEDAF.

Álvarez Menéndez, E. (2019). La relación entre el recurso de casación y el incidente de nulidad de actuaciones: el agotamiento de recursos a los efectos de interponer recurso de amparo según la jurisprudencia del TEDH. Revista General de Derecho Administrativo, 51.

Aragón Reyes, M. (2015). Algunos problemas del nuevo recurso de amparo. En A. del Moral García, J. Moreno Verdejo (dirs.). F. Herrero-Tejedor. Liber Amicorum. (pp. 233-248). Madrid: Colex.

Cancer Minchot, M. P. (2018). Recurso de casación y «vicios in procedendo». En R. C. Cancio, y L. M. Cazorla Prieto (dirs.). El interés casacional objetivo en su interpretación auténtica (pp. 233-261). Cizur Menor: Thomson Reuters-Aranzadi.

Casado Casado, L. (2020). La desprotección de los recurrentes frente a las infracciones procesales en el orden jurisdiccional contencioso-administrativo: ¿quiebra del derecho a la tutela judicial efectiva? Revista CEFLegal. Revista Práctica de Derecho 237, 137-148.

Fernández Farreres, G. J. (2015). Sobre la eficiencia de la jurisdicción contencioso-administrativa y el nuevo recurso de casación "para la formación de jurisprudencia». Revista Española de Derecho Administrativo, 174, 93-131.

García Couso, S. (2010). El nuevo modelo de protección de los derechos fundamentales tras la aprobación de la LO 6/2007: la objetivación del amparo constitucional y la tutela subjetiva de los derechos por la Jurisdicción ordinaria y el Tribunal Europeo de Derechos Humanos. Revista Europea de Derechos Fundamentales, 5, 137-167. 
- (2016). La participación del Tribunal Constitucional en la construcción europea de los derechos y libertades fundamentales: adaptarse o quedar desplazado. Revista Ceflegal. Revista Práctica de Derecho, 187-188, 115-144.

González-Varas Ibáñez, S. (2016). Comentarios al nuevo recurso de casación: artículos 86 y 87 de la LJCA tras la Ley Orgánica 7/2015, de 21 de julio. Revista Aranzadi Doctrinal, 7, 75-99.

Huelin Martínez de Velasco, J. H. M. (2017). La nueva casación contencioso-administrativa (primeros pasos). Revista General de Derecho Constitucional, 24.

Pérez de los Cobos Orihuel, F. (2017). El recurso de amparo y el recurso ante el TEDH: pautas de interacción, Actualidad Jurídica Uría Menéndez, 47, 7-16. Disponible en: https://doi.org/10.18356/37068c90-es.

Pérez Estrada, M. J. (2017). La exclusiva función del actual recurso de casación contencioso-administrativo ante el Tribunal Supremo. Revista Vasca de Administración Pública, 107, 303-328. Disponible en: https://doi.org/10.47623/ivaprvap.107.2017.1.10.

- (2019). El agotamiento de la vía judicial previa en la jurisdicción contencioso-administrativa: casación y/o nulidad de actuaciones. Revista General de Derecho Procesal, 49.

Razquín Lizárraga, J. A. (2017). El interés casacional objetivo según el Tribunal Supremo. Revista Española de Derecho Administrativo, 188, 175-202.

Recuerda Girela, M. A. (2020). Algunas cuestiones sobre el incidente de nulidad tras la reforma del recurso de casación contencioso-administrativo: el incidente contra la penúltima resolución judicial. Revista Vasca de Administración Pública, 117, 421-441. Disponible en: https://doi.org/10.47623/ivap-rvap.117.2020.10.

Triana Reyes, B. (2017). ¿Qué hacer antes de ir al amparo: recurso de casación contencioso o nulidad de actuaciones? Diario La Ley, 8929, 1. 